\title{
Mangifera indica L. Leaves Extract Induced Intrinsic Apoptotic Pathway in MCF-7 Cells by Decreasing Bcl-2 Expression and Inducing Bax Expression
}

\author{
Fitriasih $^{1}$, Siti Mega Komariyah ${ }^{1}$, Ferry Sandra ${ }^{2}$, Nenny Pratiwi ${ }^{1}$, Devi Nisa Hidayati ${ }^{1, *}$ \\ ${ }^{1}$ Faculty of Pharmacy, Universitas Wahid Hasyim, Semarang, Indonesia \\ ${ }^{2}$ Department of Biochemistry and Molecular Biology, Division of Oral Biology, Faculty of Dentistry, Universitas Trisakti, \\ Jakarta, Indonesia
}

\begin{abstract}
Extract of Mangifera indica L. has been investigated to have cytotoxic activity against MCF-7 cells. Current research was conducted to determine the cytotoxic activity of methanol extract of $M$. indica leaves (MEML) on MCF-7 breast cancer cells and to investigate on the MEML's effect on Bcl-2 and Bax expressions. M. indica leaves were extracted using soxhletation with methanol. The cytotoxic test was perfomed using MTT assay with various MEML concentrations: 15.625, 31.25, 62.5, 125, 250 and $1000 \mu \mathrm{g} /$ $\mathrm{mL}$. Meanwhile, Bax and Bcl-2 expressions of MCF-7 breast cancer cells were detected with immunocytochemical staining after treatment of MEML with concentrations of $1 / 4$ $\mathrm{IC}_{50}, 1 / 2 \mathrm{IC}_{50}$ and IC $\mathrm{C}_{50}$. The results showed that $\mathrm{IC}_{50}$ of cytotoxic activity was $308.12 \mu \mathrm{g} / \mathrm{mL}$. MEML could influence Bax and Bcl-2 protein expressions. After treatment of MEML, Bcl-2 expression was decreased while Bax expression was increased.
\end{abstract}

Keywords : Mangifera indica L., Cytotoxic, Bax, Bcl-2, MCF-7

\section{INTRODUCTION}

Based on Global Cancer Observatory Fact sheets, breast cancers is ranked 1 among all other cancers in Indonesia. It has been calculated that the breast cancer age-standardized rate (ASR) per 100,000 is 42.1 and the number of new cases in 2018 is 58,256 cases (16.7\%) (Globocan, 2018). Multiagent chemotherapy improved overall survival rate, however, the use of chemotherapy might cause side effects (Sandra and Sidharta, 2018). Therefore exploration to find the chemotherapeutic agents that have high cytotoxic activity and low side effects is necessary.

Mango is one of the plants that has anti-cancer activity. Abdullah, et al., (2014) proved ethanol kernel extract of Mangifera indica L. had cytotoxic activity against MCF-7 and MDA-MB-231 cells. Barreto, et al., (2008) identified polyphenol compound namely mangiferin, which is highly contained in leaves. Núñez Selles, et al. (2014) stated that mangiferin inhibits the activation of the nuclear factor (NF)- $\kappa \mathrm{B}$, which has a crucial role in oxidative processes, chronic inflammation and antiapoptosis (Hendarmin, et al., 2008).

The mechanism of apoptosis occurs through two pathways, through mitochondria known

Submitted: August 16, 2018

Revised: November 16, 2018

Accepted: November 16, 2018

*Corresponding author: devinisahidayati@yahoo.com 
as intrinsic pathway (Sandra, 2014) and death receptors on the cell surface, known as extrinsic pathway (Sandra, 2018). Changes in the potential of mitochondrial membranes depend on the ratio between proapoptotic protein (Bax) and antiapoptotic protein (Bcl-2) (Sandra, et al., 2001), which will decide the cell fate. MCF-7 breast cancer cell line has been reported to have Bcl-2 and Bax overexpressions (Adefolaju, et al., 2010). Based on these studies, we conducted a study to investigate the cytotoxic activity and expressions of Bax and Bcl-2 of MCF-7 cells treated with M. indica L. leaves extract.

\section{MATERIALS AND METHODS}

\section{Extract Preparation and Cell Culture}

Fresh and healthy leaves of $M$. indica L. were harvested from Wilalung village RT 2 RW 6 Gajah district Demak regency. The leaves were dried and further processed with soxhletation method using methanol to obtain methanol extract of $M$. indica leaves (MEML).

MCF-7 breast cancer cells were obtained from the Laboratory of Parasitology, Universitas Gadjah Mada, Yogyakarta, Indonesia. The cells were cultured in Dulbecco's Modified Eagle Medium (Gibco, Thermo Fisher Scientific, Waltham, MA, USA) containing 10\% Fetal Bovine Serum (Gibco) and 1\% Penicillin-Streptomycin (Gibco).

\section{3-(4,5-Dimethylthiazol-2-yl)-2,5-Diphenyl- tetrazolium Bromide (MTT) Assay}

In each well of 96-well plate, 5,000 MCF-7 cells were seeded and incubated overnight. Then, MEML was added to reach the concentrations of $15.625,31.25,62.5,125,250,1000 \mu \mathrm{g} / \mathrm{mL}$ for 24 hours. After the incubation, $0.5 \mathrm{mg} / \mathrm{mL}$ MTT reagent was added into each well, then incubated at $37^{\circ} \mathrm{C}$ for approximately 3 hours. Then added $10 \% \mathrm{SDS}$ in $0.1 \mathrm{~N} \mathrm{HCl}$ was added and incubated overnight in dark. The absorbance was measured by using an ELISA reader at $\lambda 595 \mathrm{~nm}$.

\section{Immunocytochemistry}

MCF-7 cells were seeded in 6-well plates with $5 \times 10^{4}$ cells/well density on a coverslip. Upon reaching $80 \%$ confluent, the cells were treated with $1 / 4 \mathrm{IC}_{50}, 1 / 2 \mathrm{IC}_{50}$ and $\mathrm{IC}_{50}$ of MEML for 24 hours. Then, the cells were washed, fixed with methanol, and treated with $3.7 \% \mathrm{H}_{2} \mathrm{O}_{2}$ in methanol for 10 minutes.

Afterthat, the cells were washed and treated with blocking serum for 15 minutes. The cells were further processes with mouse monoclonal anti-Bcl-2 (Dako, Carpinteria, CA, USA) or rabbit polyclonal anti-Bax (Dako) antibody for 60 minutes, biotinylated universal secondary antibody (Biocare, Pacheco, CA, USA) for 20 minutes and streptavidin HRP label (Biocare) for 10 minutes. Finally, the cells were added with DAB substrate (Dako) to visualize to the antigen-antibody bound and counterstained with hematoxylin. Expressions of Bcl-2 and Bax were observed as the brown color at the cytoplasm and membranes of MCF-7 cells under an upright light microscope. The expressions were then semiquantified using ImageJ version $1.51 \mathrm{w}$ software.

\section{RESULTS}

\section{Morphology and Viability of MEML-treated MCF-7 Cells}

The results showed that MEML had cytotoxic effect on MCF-7 cells. As shown in Figure 1, treatment of $125 \mu \mathrm{g} / \mathrm{mL}$ MEML for 24 hours caused morphological change of MCF-7 cells. Viable cells appeared as leaf-shape (Figure 1A), while dead cells as round (Figure 1B).

MEML treatment showed a dose-dependent phenomenon in inducing MCF-7 cell death. Percentage of viable MCF-7 cells was decreased along with the increase of MEML concentration (Figure 2). Based on the trendline equation, cytotoxic $\mathrm{IC}_{50}$ of MEML on MCF-7 cells was $308.12 \mu \mathrm{g}$. 
A

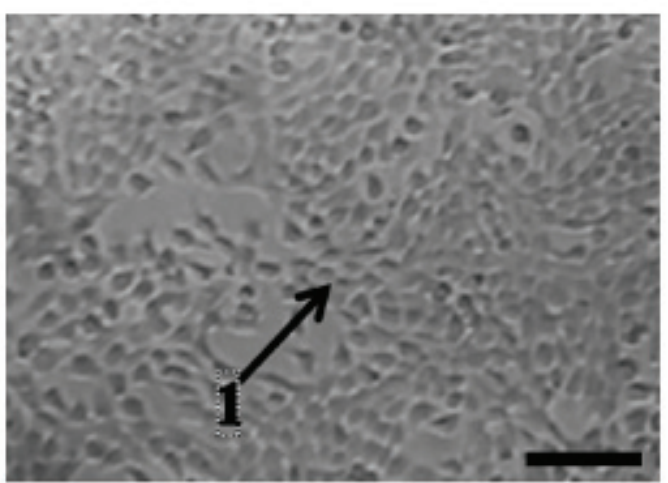

$\mathrm{B}$

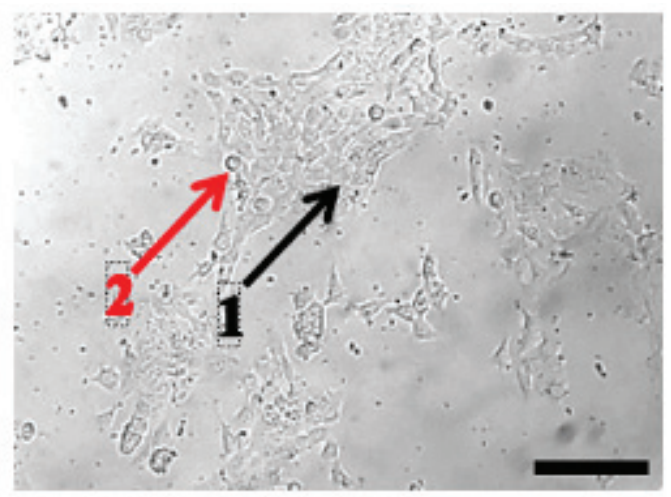

Figure 1. Morphology of MEML-treated MCF-7 cells. MCF-7 cells were seeded, incubated overnight and treated with $125 \mu \mathrm{g} / \mathrm{mL}$ MEML for 24 hours. Untreated (A) and $125 \mu \mathrm{g} / \mathrm{mL}$ MEML-treated (B) MCF-7 cells were documented under an inverted microscope. 1: viable cell, 2: dead cell. Bar: $100 \mu \mathrm{m}$.

\section{Bcl-2 Expressions of MEML-treated MCF-7 Cells}

The Expression of Bcl-2 can be seen in Figures 3. The Bcl-2 Expression semiquantifications of 0 , $77\left(1 / 4\right.$ of $\left.\mathrm{IC}_{50}\right), 154\left(1 / 2\right.$ of $\left.\mathrm{IC}_{50}\right)$ and $308\left(\mathrm{IC}_{50}\right) \mu \mathrm{g} /$ mL MEML-treated MCF-7 cells were $9.74 \%, 6.03$ $\%, 3.73 \%$ and $1.81 \%$. These results showed that the treatment of 77, 154 and $308 \mu \mathrm{g} / \mathrm{mL}$ MEML decreased the expression of Bcl-2 until 38\%, 62\% and $81 \%$, respectively.

\section{Bax Expressions of MEML-treated MCF-7 Cells}

The Expression of Bax can be seen in Figures 4. The Bax Expression semiquantifications of 0 , $77\left(1 / 4\right.$ of $\left.\mathrm{IC}_{50}\right), 154\left(1 / 2\right.$ of $\left.\mathrm{IC}_{50}\right)$ and $308\left(\mathrm{IC}_{50}\right) \mu \mathrm{g} /$ mL MEML-treated MCF-7 cells were $1.90 \%, 3.78$ $\%, 4.80 \%$ and $6.23 \%$. These results showed that the treatment of 77,154 and $308 \mu \mathrm{g} / \mathrm{mL}$ MEML increased the expression of Bax until 1.99, 2.53 and 3.28 folds, respectively.

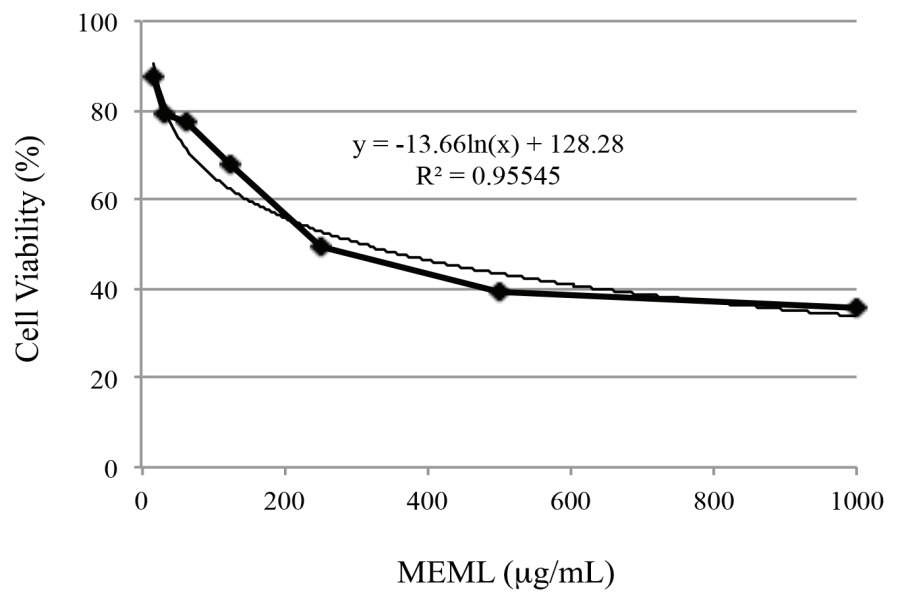

Figure 2. Viability of MEML-treated MCF-7 cells. MCF-7 cells were seeded, incubated overnight and treated with MEML in various concentrations as shown in the figure for 24 hours. Viable cells were measured with MTT assay as descibed in Materials and Methods. Results were shown in line graph. Logarithmic trendline, trendline equation and $\mathrm{R}$-squared value were shown in the graph as well. Each point shows the average of three replications. 
A

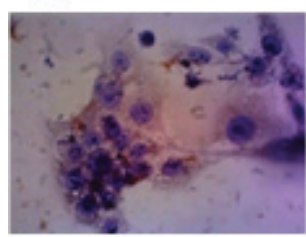

B
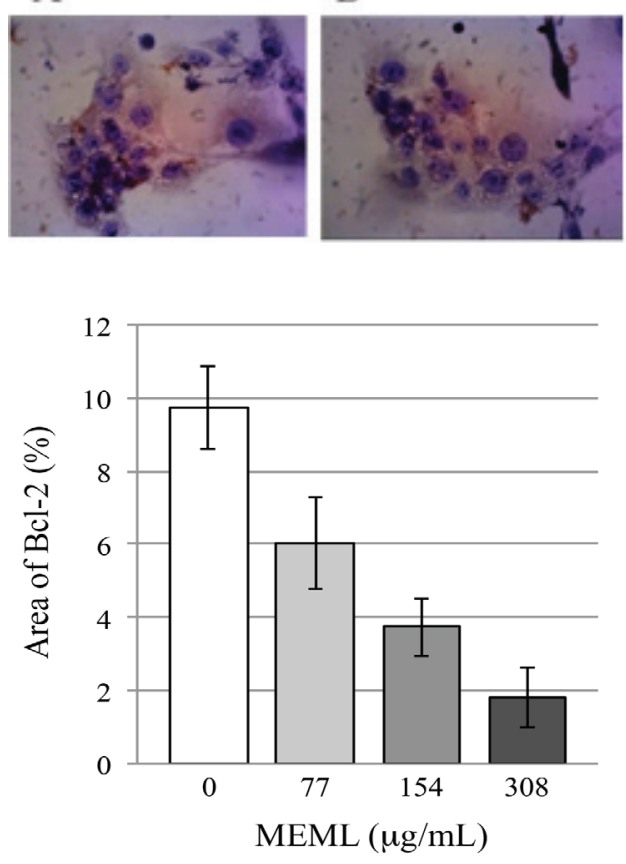

$\mathrm{C}$

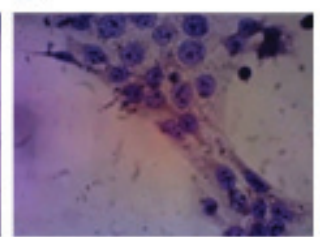

D

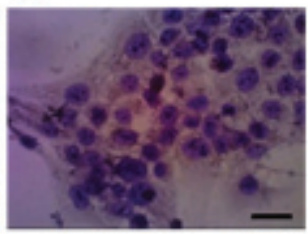

Figure 3. BCl-2 Expression of MEML-treated MCF-7 Cells. MCF-7 cells were treated with 0 (A), 77 (B), 154 (C) and 308 (D) $\mu \mathrm{g} / \mathrm{mL}$ MEML. Cells were processed with Immunohistochemistry to detect $\mathrm{Bcl}-2$ as described in Methods. Expressions of $\mathrm{Bcl}-2$ were indicated by the presence of $\mathrm{Bcl}-2$ monoclonal antibodies bonds, detected in brown color in the cytoplasm and membrane of MCF-7 cells. E: Semiquantified Bcl-2 expression with ImageJ. Bar: $50 \mu \mathrm{m}$.

A

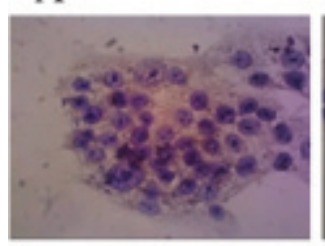

B
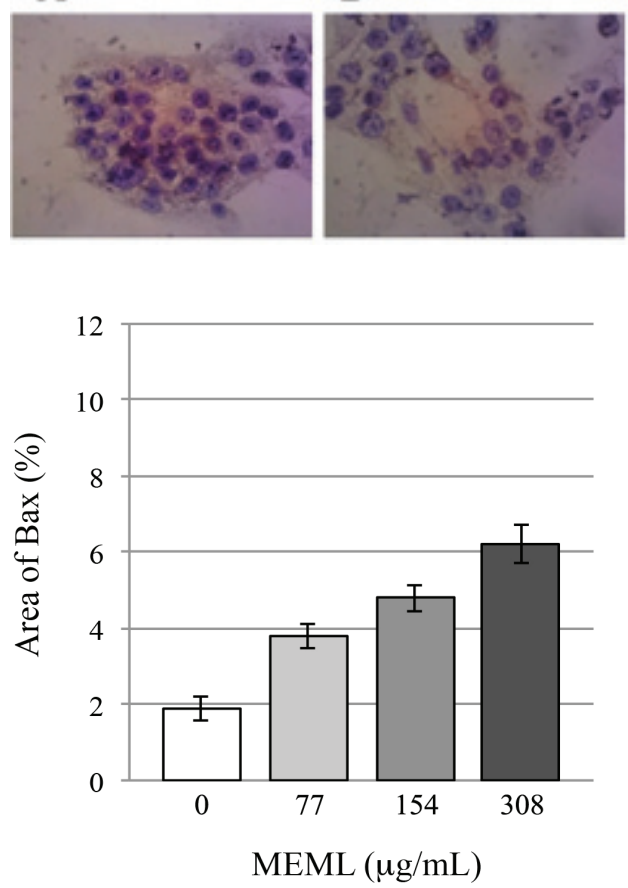

$\mathrm{C}$

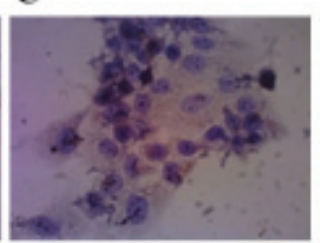

D

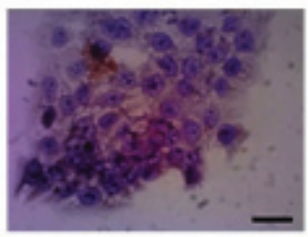

Figure 4. Bax Expression of MEML-treated MCF-7 Cells. MCF-7 cells were treated with 0 (A), 77 (B), 154 (C) and 308 (D) $\mu \mathrm{g} / \mathrm{mL}$ MEML. Cells were processed with Immunohistochemistry to detect Bax as described in Methods. Expressions of Bax were indicated by the presence of Bax monoclonal antibodies bonds, detected in brown color in the cytoplasm and membrane of MCF-7 cells. E: Semiquantified Bax expression with ImageJ. Bar: $50 \mu \mathrm{m}$. 


\section{DISCUSSION}

M. Indica L. leaves contain flavonoids, phenols, polyphenols, mangiferin, gallic acid, methyl gallate, quercetin pentoside, isoquersetin isomers (Barreto, et al., 2008). Mangiferin and gallic acid both inhibited NF- $\mathrm{KB}$ activation by

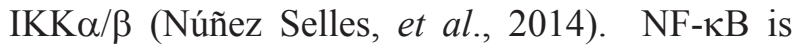
one of the transcription factors that regulate the expression of anti-apoptotic genes (Hendarmin, et al., 2008). Regulation of intrinsic apoptosis through the regulation of Cytochrome $\mathrm{C}$ release. Igney and Krammer (2002) stated that the Bcl2 expression prevents the Cytochrome $\mathrm{C}$ release from mitochondria. In the contrary, Bax will induce the Cytochrome $\mathrm{C}$ release. Within the cytosol, Cytochrome $\mathrm{C}$ will form a complex with Apoptotif Protease Activating Factor-1 (Apaf1) and Procaspase-9. This complex is called apoptosome, which activates caspase-9 (Sandra, 2014). Caspase- 9 activates caspase 6 and caspase- 7 to execute apoptosis.

Previous research has shown that mangiferin modulates apoptosis by decreasing Bcl-2 expression and increasing Bax expression in CNE2 Nasopharyngeal Cancer Cells. Mangiferin also inhibits cell proliferation through $\mathrm{G} 2 / \mathrm{M}$ phases ( $\mathrm{Li}$ Li Pan, et al., 2014). Current result showed that MEML induced apoptosis through the mitochondrial pathway by increasing the expression of Bax and decreasing the Bcl-2 expression, which will lead to the disruption of the mitochondrial membrane potential, then the release of Cytochrome $\mathrm{C}$ from the mitochondria to cytosol. However, further research is needed to confirm the suggested pathway.

\section{CONCLUSION}

MEML induces apoptosis in MCF-7 cells through intrinsic apoptotic pathway by decreasing Bcl-2 expression and increasing Bax expression. The cytotoxic $\mathrm{IC}_{50}$ of MEML on MCF-7 cells was $308.12 \mu \mathrm{g} / \mathrm{mL}$.

\section{ACKNOWLEDGEMENTS}

This work was supported by the Ministry of Research, Technology and Higher Education of the Republic of Indonesia on the Program Kreativitas Mahasiswa.

\section{REFERENCES}

Abdullah, A H., Mohammed, A S., Abdullah, Rasedee., Mirghani, Mohamed E S., and Al-Qubaisi, Mothanna., 2014, Cytotoxic effects of Mangifera indica L. Kernel extract on human breast cancer (MCF-7 and MDA-MB-231 cell lines) and bioactive constituents in the crude extract, BMC Complement. Altern. Med., 14, 199.

Adefolaju, G.A., Theron, K.E. and Hosie, M.J., 2015, BAX/BCL-2 mRNA and protein expression in human breast MCF-7 cells exposed to drug vehicles-methanol and dimethyl sulfoxide (DMSO) for 24 hrs, Niger. Med. J., 56(3), 169174.

Barreto, J.C., Trevisan, M.T., Hull, W.E., Erben, G., de Brito, E.S., Pfundstein, B., et al., 2008, Characterization and Quantitation of Polyphenolic Compounds in Bark, Kernel, Leaves, and Peel of Mango (Mangifera indica L.), J. Agric. Food Chem., 56(14), 5599-5610.

International Agency for Research on Cancer, World Health Organization, Globocan, 2018, Website, http: / /gco.iarc.fr/today/data/factsheets / populations/360-indonesia-fact-sheets.pdf, accessed on May 25, 2015.

Hendarmin, L., Kawano, S., Yoshiga, D., Sandra, F., Mitsuyasu, T., Nakao, Y., et al., 2008, An Anti-apoptotic Role of NF-kB in TNFa-induced Apoptosis in an Ameloblastoma Cell Line, Oral Sci. Int., 5(2), 96-103.

Igney, F.H. and Krammer, P.H., 2002, Death and antideath: tumor resistance to apoptosis, Nat. Rev. Cancer, 2(4), 277-288.

Núñez Selles, A.J., Daglia, M. and Rastrelli, L., 2016, The potential role of mangiferin in cancer treatment through its immunomodulatory, antiangiogenic, apoptopic, and gene regulatory effects, Biofactors, 42(5), 475-491. 
Pan, L.L., Wang, A.Y., Huang, Y.Q., Luo, Y. and Ling, M., 2014, Mangiferin Induces Apoptosis by Regulating Bcl-2 and Bax Expression in the CNE2 Nasopharyngeal Carcinoma Cell Line, Asian Pac. J. Cancer Prev., 15(17), 7065-7068.

Sandra, F., Nakamura, N., Mitsuyasu, T., Shiratsuchi, Y. and Ohishi, M., 2001, Two relatively distinct patterns of ameloblastoma: an anti-apoptotic proliferating site in the outer layer (periphery) and a pro-apoptotic differentiating site in the inner layer (centre), Histopathology, 39(1), 9398.
Sandra, F., Sudiono, J., Sidharta, E.A. Sunata, E.P., Sungkono, D.J., Dirgantara, Y., et al., 2014, Conditioned Media of Human Umbilical Cord Blood Mesenchymal Stem Cell-derived Secretome Induced Apoptosis and Inhibited Growth of HeLa Cells, Indones. Biomed. J., 6(1), 57-62

Sandra, F., 2018, Targeting Ameloblatoma into Apoptosis, Indones. Biomed. J., 10(1), 35-39.

Sandra, F. and Sidharta, M.A., 2018, Caffeic Acid Induced Apoptosis in MG63 Osteosarcoma Cells Through Activation of Caspases, Mol. Cell. Biomed. Sci., 1(2), 1-5. 